\title{
15 AQUATIC SAFETY SIGNAGE RECOGNITION AND
} COMPREHENSION

doi:10.1136/injuryprev-2012-040590h.15

${ }^{1,2} \mathrm{R}$ Andronaco, ${ }^{1} \mathrm{~B}$ Matthews, ${ }^{1} \mathrm{~S}$ Grace, ${ }^{3} \mathrm{~A}$ Adams, ${ }^{2} \mathrm{C}$ Arrowsmith. ${ }^{1}$ Life Saving Victoria, Australia; ${ }^{2}$ RMIT University, Australia; ${ }^{3}$ James Cook University, Singapore

Background Aquatic safety signs are designed to alert potential users of aquatic related hazards such as strong currents (rips), submerged rocks or dangerous marine life. Failure to recognise and understand aquatic safety signage may lead to serious consequences such as drowning or spinal injury. Limited research exists regarding effective aquatic safety signage and the extent of compliance with signs.

Aims This study aims to determine the extent of recognition and understanding of aquatic safety signage at Victorian beaches.

Methods Interviews were conducted with coastal recreation users at two bay and two ocean beaches in Victoria from February to April 2012. Participants aged 18 years or over were invited to participate in the study. Three different signage conditions were used; no signage, composite or single signs, and broken down signage. A questionnaire was developed to measure: hazard identification, likely consequences, and perceived injury severity resulting from the hazards identified; observations regarding beach hazard symbols, comprehension of the meaning of the symbols and whether changing the shape of the warning sign affects interpretation of the message.

Results 531 beachgoers responded to the survey. Of the beaches where signage was in place $45 \%$ of people observed the signage. Signage composition and hazard symbol shape did not affect recognition.

Significance The outcomes of this research provided data from which to model the design of aquatic safety signage placed on beaches. It also provides insight into signage effectiveness as a risk treatment option. 